$10.2478 / \mathrm{v} 10122-012-0004-2$

\title{
CHARACTERISTIC MORPHOLOGICAL AND SYNTACTIC FEATURES OF ENGLISH IN KENYA: A CORPUS STUDY (ICE)
}

\author{
NATALIA BUDOHOSKA
}

\begin{abstract}
Natalia Budohoska. Characteristic Morphological and Syntactic Features of English in Kenya: A Corpus Study (ICE). Lingua Posnaniensis, vol. LIV (1)/2012. The Poznan Society for the Advancement of the Arts and Sciences. PL ISSN 0079-4740, ISBN 978-83-7654-103-7, pp. 45-56.

This study discusses characteristic morphological and syntactic features of English in Kenya on the basis of the International Corpus of English (ICE) for Kenya. It contains a list of typical traits compiled following the universal criteria for describing varieties of English set up by KorTMANN (2008: xxv-xxix). The features found were confronted with the SZMrecsanyI \& KorTmann (2009: 68) concept of the inherent simplification of the new varieties of English. Finally, the amount of variation found in the ICE was placed into a wider context of other postcolonial varieties of English. The results of this analysis add to the discussion of recognizing English in Kenya as an emancipated variety of English (Budohoska 2011a, b). This study presents a high degree of characteristic features of English in Kenya, many of them shared with other recognized varieties of English. It also reveals tendencies of simplification common to New Englishes. The estimated frequencies of these features, however, are too low to reveal stigmatized forms of Kenyan English.
\end{abstract}

Natalia Budohoska, Institute of English Studies, University of Warsaw, ul. Nowy Świat 4, PL - 00-497 Warszawa; Flat 4, 15 Brookside, CB2 1JE Cambridge, UK, n.budohoska@uw.edu.pl

\section{INTRODUCTION}

In Kenya, English and Kiswahili are the two official languages while the tribal languages function as the languages of ethnic identity (BuDOHOSKA 2011a: 50-51). Tribal languages may be linked to the rural homestead, family or traditional values, Kiswahili may be associated with town life, trade, and certain kinds of jobs and English refers to the government, high status jobs and education.

This distinction immediately implies large-scale bi- or multilingualism and it is true that the individual speakers in Kenya often have a linguistic repertoire ranging from two to three, or even four, or five languages. The number of languages known and the level of competence are determined by the speaker's ethnic background but also to a very large extent by the socio-economic status and level of education. The knowledge of only one, i.e. the corresponding tribal language, is rare in contemporary Kenya since even in the most remote parts of the country intertribal communication is part of day-to-day life and brings about the necessity of knowing Kiswahili (rural and urban areas) and/or English (mostly urban areas) to be able to interact. English is speculated to be spoken by only $10-20 \%$ of 
the population (Githiora 2008: 236). Such widespread language contact creates favourable grounds for a new variety to emerge. In order to be recognized, however, the new variety of language must develop characteristic features of its own and this paper concentrates on the morphosyntactic features of English in Kenya.

\section{DATA AND THE TOOLS}

The International Corpus of English (ICE) is an ongoing project, initiated in 1990 at the University College London. It aims at collecting English language samples from various countries around the world where English functions as the first or a second language, following KACHRU's (2006: 70-71) model of the spread of English worldwide. Taken into consideration are, therefore, countries representing the "Inner circle", where English is a native language for the majority of population and the "Outer circle", where English is an official language. The goal of such a collection of subcorpora is to enable making large-scale comparisons between different varieties of English on the international level. Each ICE subcorpus is divided into 500 texts consisting of roughly 2,000 word text samples representing various kinds of spoken and written English. The total number of words for each subcorpus is approximately one million. Extracts from texts rather than whole texts are included in the corpora in order to increase the variability through increasing the number of speakers and writers.

As this study concentrates on the morphosyntactic analysis of English in Kenya, the Kenyan component (henceforth referred to as the ICE-K) was extracted from the East African subcorpus of the ICE (henceforth referred to as the ICE-EA), which includes also English in Tanzania, an issue not of interest here. It is a digitalized collection of texts gathered between 1990-1996 within the framework of the Special Research Programme on Africa. A description of the material incorporated into the ICE-EA is in Hudson-ETtLe and SCHMiEd (1999: 4-11). The minimum age limit for both, male and female, contributors, representing all walks of life, was set up as 18 . Most of them received formal education up to at least the secondary level in English, while the primary education was often obtained in native African languages. Information concerning name, gender, age, first language, and education is included in the texts where they were possible to obtain.

The contents and features of the ICE-K are discussed in NeLson et al. (2006: 2). Most importantly, a wide range of types of texts was considered in the development of the ICE. The spoken component (389,832 words) includes spontaneous dialogue, radio broadcasts, telephone conversations, scripted speeches and classroom dialogues. The written component (421,955 words), on the other hand, represents fictional writing, press reportage, editorials, popular and learned writing as well as personal and business correspondence, and student essays and exams.

For the analysis of the ICE-K, the Ant.Conc.3.2.m search software (available online) was used employing the search tools labelled as Word List and Concordance to extract the relevant tokens from the corpus. Each search for any single lexical item or their group, using Word List revealed the number of tokens together with their original contexts. This allowed verification of the lexical items under investigation after making sure that they meet the criteria of each search. The Concordance tool permits to extract words which appear in the 
company of the investigated lexical items (either preceding or following them), within a selected range of words. The Concordance analysis therefore permits exploring each token individually and in detail, making the general claims about the language under scrutiny more reliable. A detailed statistical analysis of the frequency of occurrence of the characteristic features discussed was not aimed at in this study as it is not part of the analysis performed by Kortmann (2008: xxv-xxix) and Szmrecsanyi and Kortmann (2009: 68) whose research was used as guidelines here.

\section{VARIATION ACCORDING TO WORD CLASS}

The amount of variation in the emerging varieties of English is difficult to measure precisely and only a rough estimate as compared with the standard forms was taken into account in this paper. Moreover, features described in this paper are not homogeneous throughout the ICE-K and prove to be variable rather than fixed. English in Kenya, like all other emerging varieties of English, is a mixture of equivalent standard forms and local variants. Sometimes the standard forms may be employed more frequently than the features described as characteristic.

It should also be pointed out that the items described in this paper as features of English in Kenya are not claimed to be unique to this variety of English. In fact as SCHMIED (2008, 2009) points out in his studies on African English, all the new varieties of English, at least partially share similar patterns of development in some respects, e.g. as regards simplification and regularization. The features discussed in this study should, therefore, be treated as examples of the features often characteristic of all the emerging and the emancipated varieties of English.

In order to facilitate comparative studies of the new varieties of English, KorTMANN (2008: xxv-xxix), compiled a list of 76 characteristic morphological and syntactic features, extracted from studies dealing with the grammatical properties of the non-standard varieties of English. Whenever a characteristic feature from the ICE-K corresponded with a feature listed by Kortmann (2008: xxv-xxix) as typical of the varieties of English in general, the number of that feature in agreement with Kortmann's list was given in square brackets for easy reference and to allow for future comparative studies on other varieties of English.

\subsection{NOUNS}

With reference to the noun phrase the characteristic features observed in the ICE-K concern two elements: the article and the number. In general one of the most frequent differences between Standard English and the majority of the emerging varieties of English is the irregular use of articles KORTMANN: [17] (henceforward K: and numbers in square brackets are used to refer to features listed by Kortmann 2008: xxv-xxix). Platt et al. (1984: 52-59) discuss a system of articles particularly applicable to those New Englishes which distinguish specific and non-specific nouns instead of the Standard English contrast definite vs. indefinite. The ICE-K data lack the articles, both definite and indefinite, where Standard English requires them, e.g.: 
(1)

He showed me $\varnothing$ amount and the receipt number. [S1BCE11K]

(2)

We should be with our mothers after delivery to support them to be with her let her know that she has done $\varnothing$ good job to have delivered this baby. [S2B021K]

An opposite tendency, was to insert an article where it is redundant, including the position before a plural noun, e.g.: ${ }^{1}$

$$
\text { You know they were not a people they were just children of nature before he came. [S1B003K] }
$$

He's buddy busy reading a accounts or reading you know law he's [...] finalising his profession. [S1A007K]

Finally, the ICE-K occasionally exhibits no plural markers after measure nouns K: [14]; e.g.:

These will be ready to receive the fertilised ovum and nourish it for the nine month that it will take inside the uterus. [S2B039K]

The features discussed within the class of noun phrases in the ICE-K are neither consistently used nor do they allow to draw conclusions about stigmatized differences between English in Kenya and Standard English. The frequency of the innovative features listed in this section is lower than the frequency of the corresponding Standard English forms.

\subsection{VERBS}

The characteristic features of the verb phrase in the ICE-K were divided into the subcategories of tense and aspect, verb morphology, agreement and negation. A very common feature of the emerging varieties of English is a wider range of uses of the progressive aspect and extending be + -ing constructions to all verbs affecting the distinction between stative and non-stative verbs K: [21]. According to Alo et al. (2008: 325) this applies particularly to the verbs of perception: see, hear, smell, feel, recognize, etc. The ICE-K contains examples of numerous verbs of perception used in the Progressive:

[...] I want to emphasise to fathers that this baby it's you. It's your baby so it's you. When the mother is loving this baby the mother is loving you as well. [S2B021K]

I'm not allowed to be free and I was feeling it very strongly at that time. [S1A024K]

Also instances of the use of habitual be K: [22] and do K: [23] are present in the ICE-K, cf.:

You know, one thing keeps me angered that I be separated from people like you. [W1B-SK43]

As a hides and skins officer my duty includes licensing traders. I do collect and receive the hides and skins on behalf of the Government. I do issue receipts to the customers. [S1BCE11K]

Instances were found in the ICE-K of the auxiliary do used as a tense and aspect marker K: [27], e.g.:

1 The numbers in brackets follow the numbers ascribed to texts in the ICE. 
Members familiarise themselves with the provisions of the Bill and talk to the Bill in the hope, of course, that we do come out, at the end of the discussion, with a good Bill that will become law and be implemented for the interest of society. [S1B052HK]

A feature common for the new varieties of English is the process of eliminating irregular forms. This leads to producing innovative forms usually based on regular patterns from the Standard variety. These regularised forms may become widely acceptable and replace the irregular forms or they may exist simultaneously. The number of examples illustrating this tendency in the ICE-K is, however, too small to confirm the regularization of new language patterns. In the ICE-K this tendency was noticed in the case of regularizing some verb paradigms K: [36], e.g.:

Besides this a tooth will be replaced on that original root and part outside the gum I choosed this method although it is very, very expensive. [W1B-SK03]

Boring and filling Costed 2,650 F. [W1B-SK03]

The other irregular verbs which acquired the past tense regular ending -ed included bend, break, sing, sit. Another form of levelling the preterite and past participle forms are unmarked past tense forms of irregular verbs K: [37] or replacing the past tense form with the past participle K: [39]. In the ICE-K these appeared to be rare patterns, as illustrated below:

$[\ldots]$ he visited a supermarket or something and when he was walking back to the car he find somebody admiring his car [...]. [S1BINT8K]

In Mostar uh where I been just a month ago which is uh supposed to be a unified city once again not a single step has been made towards a proper alliance between Croats and Muslims. [S2BTAL2K]

Sometimes, though not consistently, zero marks the third person singular present tense forms K: [53]. Even within a single utterance it is possible to find both forms of the third person singular, e.g.:

You know me I apply Africa's socialism at heart. Am not like Vero when she see me she me. She only talks to me when it's convenient. [S1A012K]

A tendency to delete be $\mathrm{K}:$ [57] or auxiliary have $\mathrm{K}$ : [58] was found in the complex auxiliary forms, as confirmed by the examples:

$$
\text { They } \varnothing \text { simply going to steal. [S1B022K] }
$$

I $\varnothing$ been $[\ldots]$ thinking. [S1A012K]

As regards negation, occasionally ain't is found in the ICE-K as the negated form of be $\mathrm{K}$ : [46], in both the spoken and the written component of the ICE-K, e.g.:

$$
\text { I beg and hope it ain't too late now. [W1B-SK28] }
$$

Also never was found as a preverbal negator K: [49], e.g.:

$$
\text { But he never came to the House to ask his question. [W2E014K] }
$$

Question tags tend to be limited in number in the postcolonial varieties of English and frequently invariant, non-concord tag isn't may be used for all persons K: [52], e.g.: 
The analysis of the data collected in the verb phrase provided a large number of characteristic features in the ICE-K. However, similarly to the analysis of the noun phrase, the frequency of these phenomena compared with the frequency of Standard English forms does not allow to draw any conclusions about stigmatized verbal forms functioning in the ICE-K.

\subsection{PRONOUNS}

As regards pronouns, the ICE-K reveals significantly less variation than that typical of the noun and verb phrases. A characteristic feature of English in this category in the ICE-K and other varieties of English is the regular use of special forms of the second person plural pronouns K: [3]; cf. the form you people or you guys illustrated in the examples below:

If you people do not want this House to be reasonable and put things right, we shall also do the same thing you are now doing if you do not want to keep quiet. [S1BHN12K]

So you guys are not giving me time? [S1A003K]

Occasionally, the pronoun them replaces the demonstrative those $\mathrm{K}$ : [1] in the ICE-K, e.g.:

Then the external board met and discussed them stories poems and all that. [S1A027K]

Rarely, reflexives lack the number distinction and the suffix -self is attached to the plural forms K: [6], e.g.:

[...] the only option and the easy option out to cater for this child and for ourself is probably to engage in this kind of a behaviour. [S1B031K]

Occasionally the pronoun me instead of $I$ is used in compound subjects K: [9], e.g.:

$$
\text { If anything }<\text { name }>^{2} \text { and me have nothing in common. [W1B-SK05] }
$$

Finally, a non-standard use of $u s$ was observed K: [11]; e.g.:

So you know I think, I think also that's part of the reason because like uh well the generation of Ngugi and all that they started writing when they were much much younger than us people. [S1A027K]

The frequency of the features discussed under the label of pronouns is, however, very low, which means that the Standard English forms remain dominant. The most stigmatized and most frequent feature of this word class reflects the disregard of gender distinction of the referents and the domination of the form he.

2 Because the language samples in the ICE-K are anonymous, the names are in some cases removed. 


\subsection{ADJECTIVES AND ADVERBS}

As the final step, the characteristic features of adjectives and adverbs were looked into and five features were distinguished in the ICE-K. Adverbs other than degree modifiers may acquire, though rarely, the same form as adjectives K: [42] and, occasionally, degree modifier adverbs may lack the suffix -ly K: [43], e.g. (27-28):

I just wanted to get you something really special, because in my whole life, very few people have treated me as nice as you have without expecting anything in return, and I really meant it when a said you were a 'mighty good man'. [W1B-SK36]

$[\ldots]$ he decided also to do law and is a very successful lawyer because law is complete different discipline as you go to university. [S1B028K]

It has also been found that both regular and irregular adjectives may assume the form of double comparatives K: [19], e.g. (29-30):

\footnotetext{
You start having a very dark area on your breast which is called the aureola and becomes more darker when you are expecting [...]. [S2B027K]

And when drawn by rumours or bridges they move their families to the city where they find the pay more better and the cost of living is far higher than in the village they left. [S2B033K]
}

The frequency of each of these features in the word class types of adverbs and adjectives, however, is too low to claim that these features are stigmatized.

Although the total amount of characteristic features discussed in this paper is impressive, the amount of tokens representing each of them is not. These features may be seen as the general tendencies of the English language in Kenya confirming that some degree of departure from Standard English takes place. In the data provided in the ICE-K, the Standard forms remain dominant. In order to further verify the frequency of these tendencies in present-day Kenya, additional research is needed, e.g. through elicitation tests.

\section{COMPLEXITY VS. SIMPLICITY OF ENGLISH IN THE ICE-K}

A significant element of the qualitative study of the characteristic features of the varieties of English pointed out by SzMrECSANYI \& KorTMANN (2009: 68), is the notion of complexity/complexification vs. simplicity/simplification. This widely debated issue centres around the so-called "equi-complexity axiom" (or "equi-complexity dogma") originating in the American Structuralism of the 1950s. According to it all the grammars of all the languages are equally complex in terms of morphology and syntax allowing for the compensation of complex morphological features for simpler syntax and vice versa. This assumption is based on the fact that all languages have similar roles to fulfil for the speakers and hence all languages must be equally complex. This concept, however, refers to languages rather than varieties of language and when discussing the latter, ceases to be valid. An opposite view is presented by McWHORTER (2001: 162) who stated in his work that there is no equicomplexity between languages and that pidgins and creoles tend to be simpler than the rest of the world languages. This concept was also supported by TRUdGILL (2000: 372) who claimed that pidgins and creoles undergo the process of the loss of redundancy, irregularity 
and increasing transparency. Trudgill also distinguishes the typological split between highcontact and low-contact varieties of English. According to this distinction English in Africa is an example of a high-contact variety which implies simplification. The validity of the claim that the varieties of English undergo a process of simplification will be investigated here in light of English in Kenya.

In order to make conclusions regarding the morphological and syntactic complexities of English in the ICE-K and its potential simplification, the analysed features were classified into three groups according to facets of complexity taken from SzMrECSANYI \& KoRTMANN (2009: 68-71): (a) quantitative complexity (increasing the size of the marker without yielding to added communicative bonus), (b) L2-acquisition complexity (the difficulty individual morphosyntactic features pose to adults in acquiring a second language and known to recur in interlanguages) and (c) complexity deriving from irregularities and low transparency (simplifying irregular, lexically conditioned grammatical morphemes). The implementation of such divisions permits to qualitatively measure the complexities of the varieties of a language. The first of the described categories reflects an increased complexity while the remaining two reflect a simplification.

All of the characteristic features found in the ICE-K were discussed in agreement with this classification in order to draw conclusions about the potential simplification of English in Kenya. Some features in the ICE-K could not be classified into these three groups and were hence treated as neutral (neither simplifications nor complexifications). These include:

[1] them instead of the demonstrative those,

[3] special forms or phrases of the second person plural pronoun,

[9] myself/meself in a non-reflexive function,

[11] non-standard use of $u s$, nouns denoting countries used as adjectives.

The remaining two groups also reflect the simplification of language. The features labelled as L2-acquisition complexity are centred around the aspect of omitting or overgeneralizing inflectional markings and preference for semantic transparency. The features found in the ICE-K classified in this category include:

[6] lack of number distinction in reflexives,

[8] generic he/his for all genders,

[14] absence of plural marking after measure nouns,

[27] do as a tense and aspect marker,

[36] levelling of the preterite and past participle verb forms: regularization of irregular verb paradigms,

[37] levelling of the preterite and past participle verb forms: unmarked forms,

[46] ain't as the negated form of have,

[52] invariant, non-concord tags,

[53] invariant present tense forms due to the zero marking of the third person singular,

[57] deletion of $b e$.

The last category includes the features which serve a further simplification of a language such as regularization, loosening or levelling structures. The following features found into the ICE-K include:

[17] the irregular use of articles,

[19] double comparatives and superlatives,

[21] wider range of uses of the Progressive,

[22] habitual be (e.g. He be sick),

[23] habitual do (e.g. He does catch fish pretty), 
[39] levelling of the preterite and past participle forms: participle replacing the past form,

[42] adverbs (other than degree modifiers) having the same form as adjectives,

[43] degree modifier adverbs lacking - $l y$,

[49] never used as a preverbal negator,

[58] deletion of the auxiliary have.

There are a total of 21 features found in the ICE-K which, according to SZMRECSANYI and KorTMANN (2009: 68-71), illustrate changes leading to the simplification of language. It can be concluded that changes in the English language in Kenya as reflected in the ICE-K indicate a process of simplification. The number of examples to illustrate each feature is nonetheless too low to make valid claims concerning the existence of Kenyan English as a stigmatized and simplified variety of English. Nonetheless an observed tendency to simplify complex structures encourages further research into this matter.

\section{OVERVIEW OF CHARACTERISTIC FEATURES}

It is difficult to describe innovations in non-standard Englishes strictly for what they are, without comparing them to the norms of a native language or Standard English. As the varieties of English around the world have received a considerable amount of attention over the past decades it is also worth to include them in this research as a point of reference. When describing a particular variety of language a balance between concentrating on unique and on common qualities needs to be maintained. The unique features are appealing to the researcher, but confirming the common pattern of a development for several varieties should not be underrated.

Although countless languages in Africa and Asia influence the Englishes functioning there, numerous common structural features are shared between the emerging and the recognized varieties of English. In an effort to put the amount of variation found in the ICE-K into context, the features corresponding with KoRTMANN's list (2008: xxv-xxix) referring to word classes were compared with data available for other varieties of English. For this purpose a summary made by Mesthrie (2008: 624-635) was consulted. Kortmann's list of 76 features was divided into 11 categories, 8 of which refer to word classes and comprise 60 features. The overall amount of features in the ICE-K and in each of the varieties used as a point of reference are presented in Figure 1 which shows the amount of variation in the eight varieties of postcolonial English: Cameroon, Ghanaian, Indian, Malaysian, Nigerian, Pakistani, Singapore and English in Kenya. It can be seen that the number of characteristic features in the ICE-K significantly exceeds the number in other varieties. These results, however, show the number of features regardless of their frequency and consistency of appearance because a full quantitative analysis was not performed by Mesthrie (2008) or in this study.

Additionally, basing on this list of the most common features of the varieties of English, KoRTMANN \& SZMRECSANYI (2004: 1154-1155) created a hierarchy of the most frequent morphosyntactic features across 46 varieties of English (both L1 and L2). The amount of variation in the ICE-K was then confronted with a wider selection of the varieties of English, including varieties other than postcolonial The aim was to check how many of the features exhibited by English in Kenya are features most frequent in other varieties of English. 


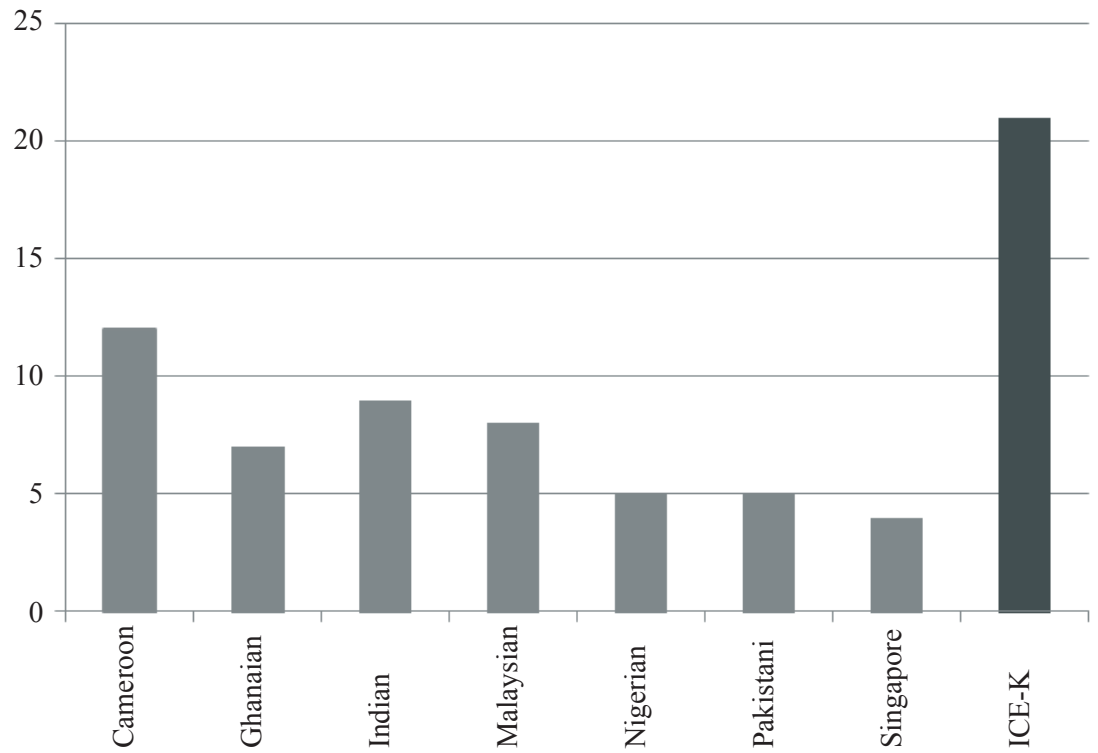

Fig. 1. Kortmann's features across 7 postcolonial varieties of English

The list of features connected with word classes was confronted with the data analysed in this study and the results are presented in Table 1.

Table 1 shows that almost half of the most frequent features are related to the noun phrase structures $[3,6,9,10,14,17,19]$. Out of the 13 most frequent morphosyntactic features in the varieties of English worldwide, English in Kenya reflected 9. In bold are marked

Table 1. The most common morpho-syntactic features of non-standard Englishes worldwide

\begin{tabular}{|c|c|c|c|}
\hline Number & Feature & $\begin{array}{l}\text { No. of varieties world- } \\
\text { wide where feature } \\
\text { is attested }\end{array}$ & ICE-K \\
\hline [10] & me instead of I in coordinate subjects & 40 & - \\
\hline [49] & never as preverbal negator & 40 & - \\
\hline [42] & $\begin{array}{l}\text { adverbs (other than degree modifiers) have the same } \\
\text { form as adjectives }\end{array}$ & 39 & + \\
\hline [14] & absence of plural marking after measure nouns & 37 & + \\
\hline [44] & multiple negation/negative concord & 35 & - \\
\hline [43] & degree modifier adverbs lack - $l y$ & 35 & + \\
\hline [3] & $\begin{array}{l}\text { special forms or phrases for the second person plural pro- } \\
\text { noun }\end{array}$ & 34 & + \\
\hline [25] & $\begin{array}{l}\text { levelling of difference between Present Perfect and } \\
\text { Simple Past }\end{array}$ & 34 & - \\
\hline [19] & double comparatives and superlatives & 34 & + \\
\hline [17] & irregular use of articles & 33 & + \\
\hline [36] & $\begin{array}{l}\text { levelling of preterite and past participle verb forms: } \\
\text { regularization of irregular verb paradigms }\end{array}$ & 32 & + \\
\hline [9] & myself/meself in a non-reflexive function & 30 & + \\
\hline [6] & lack of number distinction in reflexives & 30 & + \\
\hline
\end{tabular}


those features which, according to Kortmann \& SzMrecsanyi (2004: 1182-1183), are the most widespread features in Africa. Although the frequency of these features in the ICE-K was too low to claim that they are stigmatized, it has been shown that English in Kenya is undergoing a process of nativization similar to the patterns exhibited by other varieties of English.

\section{CONCLUSION}

The characteristic morphosyntactic features found in the ICE-K suggest the occurrence of a wide range of variation in English in Kenya. Moreover, English in Kenya proved to share features with other established varieties of English (e.g. irregular use of articles, overgeneralization of the progressive aspect, invariable tag questions, double comparatives, etc. and tendencies towards simplification). The observations of morphosyntactic features characteristic for the ICE-K in this study hint at a possible diverging development from Standard English. The non-standard forms are, however, still less frequent than the standard ones, but these tendencies are noticeable and might develop into stigmatized forms in the future.

Further analyses of English in Kenya on different language samples would reveal more details concerning the consistency of the characteristic variation confirming which features appear more regularly. The inclusion of Kenyan English in the list of the potentially emerging varieties of postcolonial English is nonetheless fully justified.

\section{REFERENCES}

Alo Moses A., Mesthrie Rajend. 2008. "Nigerian English: Morphology and Syntax.” In: Mesthrie 2008: 323339.

Bolton Kingsley, Kachru Braj B. (eds.). 2006. World Englishes. Critical Concepts in Linguistics. Vols. 1-6. Oxon: Routledge.

BuDoноsкa Natalia. 2011a. "Language as a Means of Expressing Identity in a Multilingual Reality: The Place of English in Kenya Today." Anglica 20, 37-52.

Budohoska Natalia. 2011b. "Formality as a Feature of Postcolonial English in Kenya: A Contrastive Analysis Based on the International Corpus of English." Styles of Communication 3, 5-26.

Githiora Chege. 2008. "Kenya: Language and the Search for a Coherent National Identity." In: Simpson 2008: 235-251.

Hudson-Ettle Diana M., Schmied Josef. 1999. Manual to Accompany the East African Component of the International Corpus of English: Background Information, Coding Conventions and Lists of Source Texts. Chemnitz: University of Technology, Department of English.

Kachru Braj B. 2006. "Agony and Ecstasy". In: Bolton \& Kachru 2006: vol. 1, 69-88.

Kachru Braj B., Kachru Yamuna, Nelson Cecil L. (eds.). 2009. The Handbook of World Englishes. Chichester: Wiley-Blackwell.

Kortmann Bernd. 2008. "List of Features: Morphology and Syntax." In: Mesthrie 2008: vol. 4, xxv-xxix.

Kortmann Bernd, Szmrecsanyi Benedikt. 2004. "Global Synopsis: Morphological and Syntactic Variation in English.” In: SCHNEIDER et al. 2004: vol. 2, 1142-1202.

McWhorter John. 2001. The Power of Babel. New York: Times Books a division of Henry Holt and Co.

Mesthrie Rajend (ed.). 2008. Varieties of English. Vol. 4. Africa, South and Southeast Asia. Berlin: Mouton de Gruyter.

Nelson Gerald, Wallis Sean, AARTs Bas. 2006. The International Corpus of English. The British Component Release 2. The Diachronic Corpus of Present-Day Spoken English. Getting Started with ICECUP 3.1. London: Survey of English Usage, University College London. 
Platt John, Weber Heidi, Mian Ho. 1984. The New Englishes. London: Routledge.

Sampson Geoffrey, Gil David, Trudgill Peter (eds.). 2009. Language Complexity as an Evolving Variable. Oxford: Oxford University Press.

Schmied Josef. 2008. "East African English (Kenya, Uganda, Tanzania): Morphology and Syntax." In: Mesthrie 2008: vol. 4, 451-472.

Schmied Josef. 2009. "East African Englishes.” In: Kachru et al. 2009: 188-202.

Schneider Edgar W., Burridge Kate, Kortmann Bernd, Mesthrie Rajend, Upton Clive (eds.). 2004. A Handbook of Varieties of English. Vol. 2. Berlin: Mouton de Gruyter.

Simpson Andrew (ed.). 2008. Language and National Identity in Africa. Oxford: Oxford University Press.

SZMrecsanyi Benedikt, Kortmann Bernd. 2009. "Between Simplification and Complexification: Non-standard Varieties of English Around the World." In: SAMPSON et al. 2009: 64-79.

Trudgill Peter. 2000. Sociolinguistics. An Introduction to Language and Society. London: Penguin Books.

Allatum die 14 mensis Decembris anno 2011 